\title{
THE INCLUSION OF IN-PLANE STRESSES IN DELAMINATION CRITERIA
}

\author{
Matthew T. Fenske \\ NASA Goddard Space Flight Center \\ University of Maryland \\ Department of Aerospace Engineering \\ Anthony J. Vizzini ${ }^{\dagger}$ \\ University of Maryland \\ Department of Aerospace Engineering
}

\section{$\underline{\text { Abstract }}$}

A study of delamination is performed including strength of materials and fracture mechanics approaches with emphasis placed on methods of delamination prediction. Evidence is presented which supports the inclusion of the inplane stresses in addition to the interlaminar stress terms in delamination criteria. The delamination can be modeled as a resin rich region in between ply sets. The entire six component stress state in this resin layer is calculated through a finite element analysis and inputted into a new Modified Von Mises Delamination Criterion. This criterion builds onto previous criteria by including all six stress components. The MVMDC shows improved correlation to experimental data.

\section{Problem Scope}

The problem of free edge delamination in composite laminates has been studied for many years. While much progress has been made, there still exists the need for simple tools with which

- Graduate Student, member AIAA

'Associate Professor, Associate Fellow AlAA, member AHS and ASC

Copyright 1998 by the American Institute of Aeronautics and Astronautics, Inc. No copyright is asserted in the United States under Title 17, U.S. Code. The U.S. Govemment has a royalty-free license to exercise all rights under the copyright herein for Govemmental Purposes. All other rights are reserved by the copyright owner. designers can evaluate candidate laminates for their propensity to delaminate. Such a tool could improve applications where delamination failures are either expected or would be very detrimental. Delamination criteria have been proposed in recent years, however this investigation will explore an alternate approach.

There are two main routes taken when studying the free-edge delamination problem: strength of materials and fracture mechanics. The strength of materials approach defines failure to occur when a critical stress state is reached based on material allowables. On the other hand, the fracture mechanics approach suggests that the initiation and growth of a crack depends on the energy state at that local station. In the present study delamination initiation is considered the failure of the part. The growth of the delamination, stable or unstable, is the continuation of that failure and is not addressed.

\section{Previous Work in Delamination Criteria}

Among the first to research the problem were Puppo and Evenson' who studied delamination by modeling anisotropic layers separated by thin isotropic shear layers. They recognized the stress conditions and laid the foundation for further study. Pipes and Pagano ${ }^{2 \cdot 8}$ followed with a series of studies over a number of years. Their efforts dealt mainly with the mechanics of the free edge problem and solution techniques for the stresses including finite difference, elasticity, and global-local solutions. They also investigated the effects of laminate 
thickness and stacking sequence. They demonstrated the existence of interlaminar stresses in a boundary layer near the free edge of a laminate. This boundary layer is suggested to be on the order of the laminate thickness. These interlaminar stresses can become large and lead to delamination. The interlaminar stresses and coordinate orientation are shown in Figure 1. They also concluded that the sign and magnitude of these stresses are functions of the material properties, fiber directions, thickness and stacking sequence. The stress condtion as calculated by Pipes and Pagano is shown in Figure 2. Pipes and Daniel" provided experimental verification of Pipes and Pagano results. They also concluded that a three-dimensional stress field arises in a boundary layer of approximately one laminate thickness from the free edge.

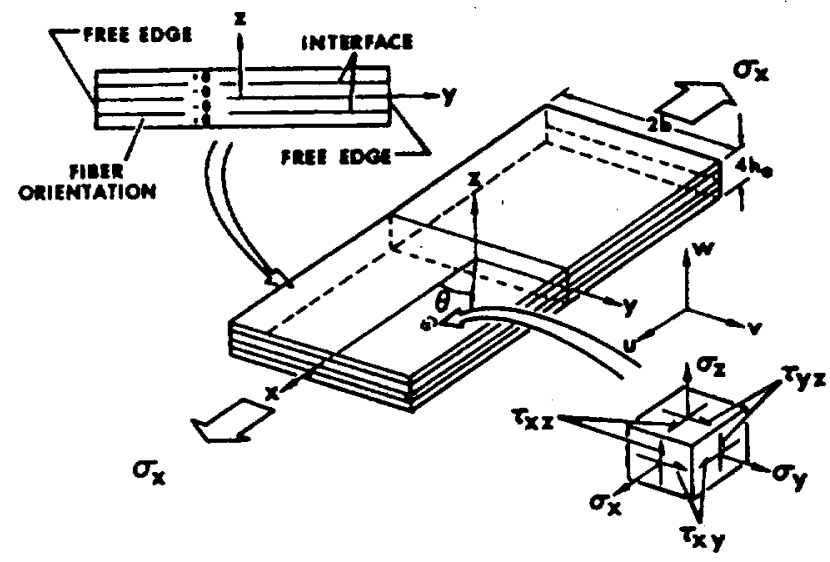

Figure 1: Laminate Coordinate System and Stress directions (from Jones ${ }^{\circ}$ )

Isakson and Levy" performed some early finite element analyses by modeling plies as homogeneous, orthotropic membranes separated by isotropic shear layers which only develop interlaminar shear stresses. They calculated the interlaminar stresses and found decent agreement with existing values. Rybicki' ${ }^{12}$ extended the procedure to a three-dimensional analysis which achieved better agreement with Pagano solutions. The in-plane stresses at the ply interface were also calculated at the edge and compared with values obtained from the middle of the laminate.

As the stress state at the free edge became more characterized, some researchers began to suggest that the interlaminar stress state became singular at the edge. This was investigated by Wang and Crossman ${ }^{13}$ who studied the singular behavior through finite element methods with fine mesh resolution. They calculated significant in-plane stresses as well as interlaminar stresses and suggested that these singular stresses dissipated into the material through a stress relaxation that degrades the material in that local region. Hsu and Herakovich ${ }^{14}$ provided mathematical evidence of singular interlaminar shear stresses and a finite interlaminar normal stress. Wang and $\mathrm{Choi}^{\text {is }}$ performed an extensive analysis on the edge singularity and concluded that the state of stress is inherently three-dimensional and that the interlaminar shear term exhibits a weak singularity which is dependent only on the material elastic constants.

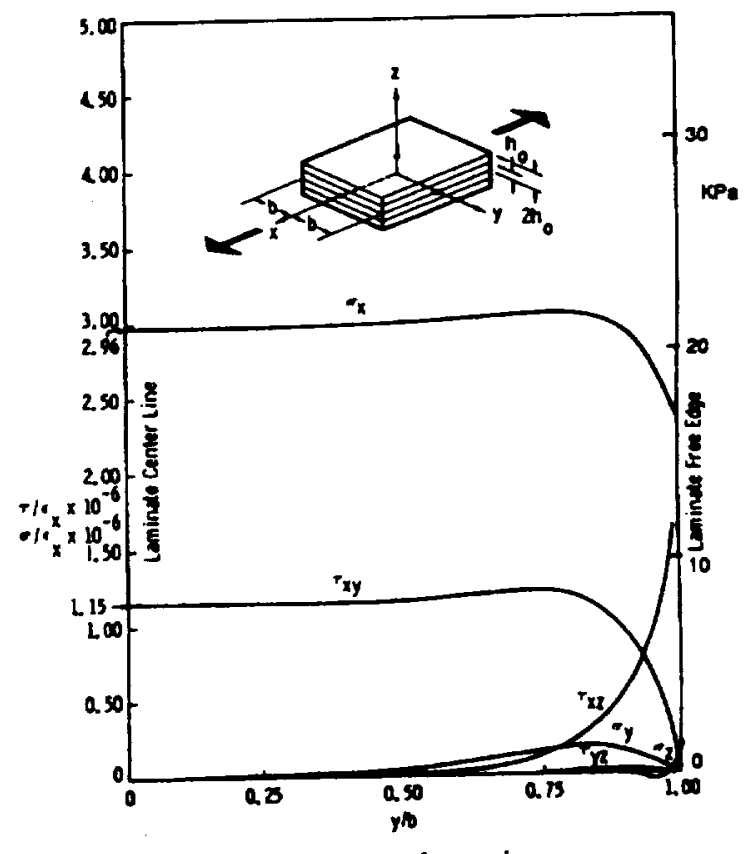

Figure 2: Interlaminar stresses as computed by Pipes and Pagano (trom Pagano')

As the development of the stress state at the free edge matured, the treatment of these possibly singular stresses in a quantitative sense became important. The need to address this mathematical behavior with a physical quantity was required. Whitney and Nuismer ${ }^{10}$ introduced the idea of an average stress in notched composite laminates. Their model averaged the 
longitudinal stress over a certain distance and predicted failure when this average stress exceeded a critical value based on material properties. This concept of the average stress was applied to the free edge by Kim and Soni ${ }^{17 .}{ }^{18}$ who averaged stresses over an arbitrary critical length of one ply thickness from the free edge.

Many strength of materials models for delamination described thus far in this paper have focused on the interlaminar shear and normal stresses as the sole contributors to delamination. Much debate is given to the extent which either or both the interlaminar normal stress, $\sigma_{z z}$, and the interlaminar shear stress, $\sigma_{x a}$ contribute to delamination. Also debated is how the sign of these terms changes their contribution. Early speculation by Pipes et $\mathrm{al}^{19}$ suggested that delamination is a complex condition where stresses and failures interact. This notion of interaction was submitted by Kim and Soni ${ }^{18}$ with the interlaminar normal and shear stresses. While the in-plane stresses have been calculated as significant, they have not been considered as playing a role in delamination. Traditionally the inplane and out-of-plane stresses have been placed into separate criteria. This is primarily due to the consideration of delamination as the failure of an interface between plies rather than a region between plies.

In a similar development, fracture mechanics has been applied to the delamination of composite materials. The underlying premise is that a delamination is a crack in the thin, isotropic, homogeneous, and brittle matrix material between two layers of fibers. There is a distinction between delamination and transverse cracking. Several researches who pursue the application of fracture mechanics to composite materials include transverse cracking as well as delamination in their studies. Fish and Lee ${ }^{20}$ demonstrated how the strain energy release rate significantly increases with the onset of transverse cracking. In addition, Reifsnider et $a^{21}$ suggested that delamination interacts with transverse cracking in 90 degree plies. The present study considers transverse cracking a different failure mode and an attempt was made to only investigate laminates which do not show a propensity for transverse cracking.

Rybicki $^{22}$ was among the first to discuss how a delamination could grow by the release of strain energy in sufficient quantity to create new surface area. This strain energy release rate or fracture toughness was investigated through finite element methods. Wang and Crossman ${ }^{23}$ and Crossman et $\mathrm{al}^{24}$ studied the application of the strain energy release rate, $G_{c}$ to delamination both analytically and experimentally. They assumed that the strain energy release rate for delamination and transverse cracking were the same. S.S. Wang $^{25}$ studied mixed-mode stress intensity factors and $G_{c}$ terms. His findings show that for angle ply laminates delamination is a threedimensional effect. An extensive examination of the application of fracture mechanics to composites is by O'Brien ${ }^{26 .}{ }^{27}$. The fracture mechanics approach is justified by the nature of the singular stress state which precludes the comparison with any strength parameter. He developed a simple expression for the strain energy release rate by comparing the difference in strain energy between a delaminated portion and an undelaminated portion of a laminate by comparing the two modulii. This relation can be used to determine a critical value of strain energy release rate and can be used to predict delamination. Assumptions of delamination size and strain energy are required. O'Brien also concluded that interlaminar flaws at the free edge either initially in the material or caused by a stress singularity do not cause delamination until a critical strain energy release rate is reached.

In recent years, Brewer and Lagace ${ }^{20}$ have developed a criterion under the strength of materials approach which utilizes average stresses compared with laminate strength terms. The stress state was calculated through the force balance method developed by Kassapoglou and Lagace $^{20}$. Their Quadratic Delamination Criterion (QDC) predicts failure based on critical values of both interlaminar shear and normal stresses. The QDC is a two parameter model in which the averaging dimension and interlaminar shear strength serve as fitting parameters. In some cases the interlaminar shear was held constant and the averaging dimension was used solely as a fitting parameter. Their analytical work was correlated to a series of experiments by comparing predicted values of delamination onset from both the QDC and strain energy release rate method to measured data. It is the intent of this work to extend the concept of the QDC to include all stress components and provide comparable agreement with the data. 


\section{Free Edge Stresses}

At the free edge of a flat laminate loaded in axial tension there arises a six component stress state which contains significant interlaminar shear and normal terms. These stresses become large within a boundary layer which has been suggested is on the order of the laminate thickness $^{8.9}$. These interlaminar stresses arise from mismatches in elastic properties between the plies. The laminate coordinate system, stress designations and the stress distribution are shown in Figures 1 and 2.

The calculation of these stresses has been investigated for many years as was described earlier. In an effort to develop a design tool it is desirable to simplify these calculations as much as possible. Modern computer methods have enabled this through simple and efficient finite element methods which were employed for the calculation of the stress state.

When considering the full stress state at the free edge, it is important to recognize the continuity of each of the components. The interlaminar stresses are continuous through the thickness at the free edge, but the in-plane stresses are not. In a [0/90], laminate the difference in the in-plane stresses in the two plies is obvious. At the interface between two ply sets an additional layer is considered which represents the resin rich region. This region is an artifact of the manufacturing process and is the site of delamination investigation. Through finite element methods, it is possible to obtain the six component stress profile in the region and subsequently input them into a criterion for delamination prediction.

A finite element analysis was employed which captured both the material and geometric considerations of the edge of a flat laminate in axial tension. The stress state at the free edge was determined using a quasi-three-dimensional finite element approach with a 12 degree-offreedom assumed-stress hybrid element based on the Hellinger-Reissner principle ${ }^{30,31}$. A constant strain loading was applied which is continuous through the thickness. The model consisted of elements both through the thickness and along the width of a laminate. A resin layer was modeled between each of the ply sets. This layer allowed for the direct calculation of the in-plane stresses which are not continuous through the thickness at the edge. The full six component stress state was calculated in the resin region. A closeup of the edge of a typical model is shown in Figure 3 for a simple four ply laminate, [15/-15]. The total width of the model extends to a large number of ply thicknesses to ensure the recovery of classical laminated plate theory in the center of the laminate. The element size at the edge is one quarter ply thickness in width and increases in size away from the edge. The element size in thickness is constant throughout the model and is one half ply thickness. The resin layer element thickness is one tenth ply thickness.

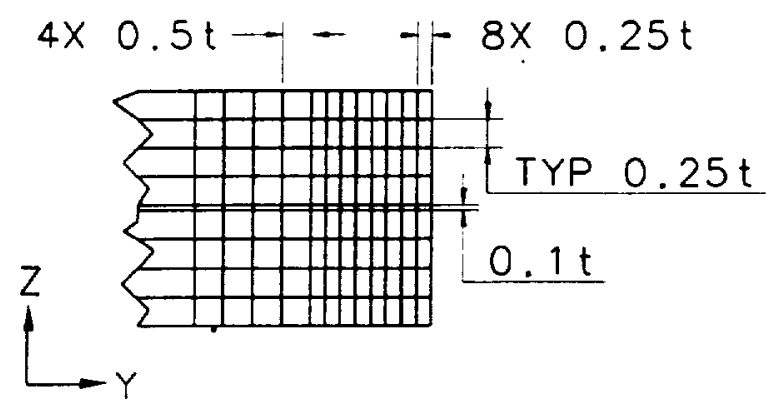

Figure 3: Finite element mesh at the edge of a [ \pm 15$]$. laminate.

Figure 4 shows the profile of all six stress components near the free edge. The stresses obtained show excellent agreement with those obtained by other researchers using other methods ${ }^{8}$. Some additional runs were made to investigate the effect of element size on the average stress levels. Clearly, the singularity at the edge yields an increasing interlaminar shear value with decreasing element size. In the finite element analysis, the element size was kept to a practical level. The arbitrary averaging dimension was selected to be on the order of the laminate thickness and the average stresses over this distance were examined for various element resolutions. It was observed that one quarter ply thickness elements in width sufficiently captured the stress levels while remaining a practical size. Other iterations with finer meshes did not produce a significant change in average stress values. 


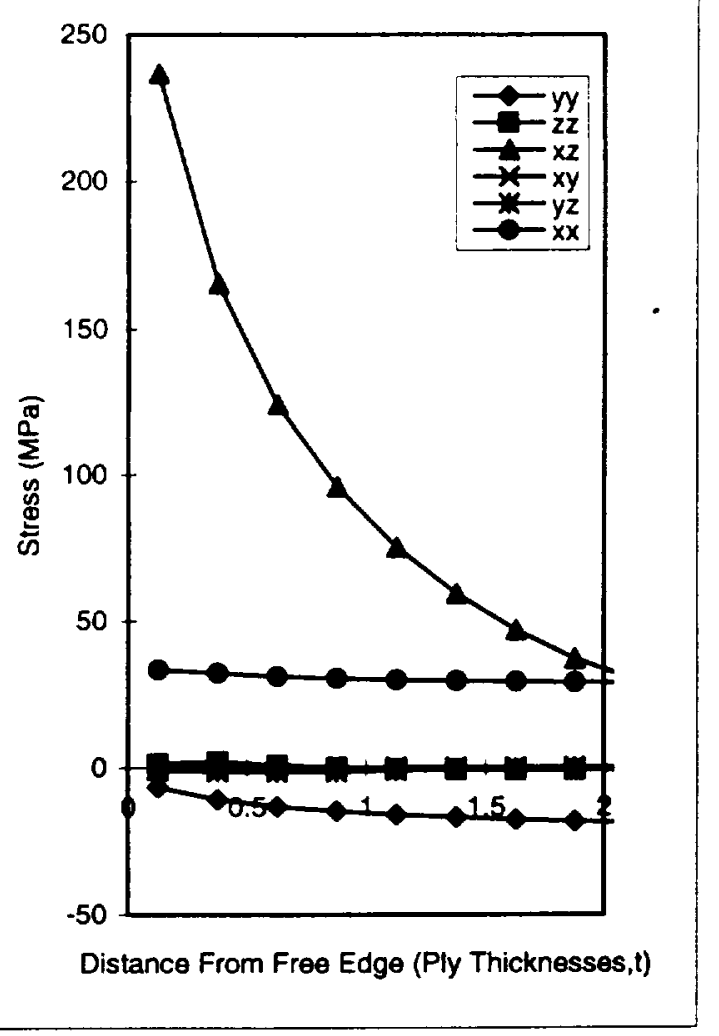

Figure 4: Stress distribution at the $\theta d g \theta$ of a [ \pm 15$]_{\text {. laminate. }}$

\section{Quadratic Delamination Criterion ${ }^{28}$}

As was mentioned earlier, the Quadratic Delamination Criterion indicates delamination by comparing interlaminar shear and normal stresses with appropriate laminate strengths. The stresses used are average values computed over an arbitrary averaging dimension. The QDC is of the form:

$\left(\frac{\bar{\sigma}_{1 z}}{z^{s 1}}\right)^{2}+\left(\frac{\bar{\sigma}_{2 z}}{z^{s 2}}\right)^{2}+\left(\frac{\bar{\sigma}_{z z}^{t}}{z^{t}}\right)^{2}+\left(\frac{\bar{\sigma}_{z z}^{c}}{z^{c}}\right)^{2}=1$

where:

$Z^{\prime}=$ Interlaminar shear strength

longitudinal shear directions

$Z^{2}=$ Interlaminar shear strength in

transverse shear directions

$Z^{\prime}=$ Tensile interlaminar normal

strength

$Z^{c}=$ Compressive interlaminar normal

strength
It was concluded that the effect of the $\sigma_{2 x}$ term is negligible and that the compressive $\sigma_{z z}$ term is either negligible or predicts an initiation value much greater than in-plane failure values. Therefore, only tensile values of interlaminar tension were considered. The following form was used for correlation to the experimental data:

$$
\left(\frac{\bar{\sigma}_{12}}{z^{31}}\right)^{2}+\left(\frac{\bar{\sigma}_{z z}^{t}}{Z^{1}}\right)^{2}=1
$$

Several researchers have concluded that the interlaminar shear term dominates delamination while others postulate that the tensile interlaminar normal term gives rise to the failure. This criterion contains both terms, however delamination is still attributed solely to out-of-plane stresses.

The averaging dimension was optimized to fit the data best at $0.178 \mathrm{~mm}$ or about 1.33 ply thicknesses. The interlaminar shear strength was assumed to be $105 \mathrm{MPa}$ which is consistant with values for this material system found in the literature. This value, as suggested by $\mathrm{Kim}$ and Soni" is the in-plane shear strength of the material.

\section{Proposed Criterion}

The proposed Modified Von Mises Delamination Criterion (MVMDC) builds on the QDC by retaining all stress components and ply strength values and is of the following form:

$$
\left(\frac{\bar{\sigma}_{1}^{2}-\bar{\sigma}_{1} \bar{\sigma}_{2}+\bar{\sigma}_{2}^{2}}{R^{\prime} R^{c}}+\frac{\left(R^{c}-R^{\prime}\right)\left(\bar{\sigma}_{1}+\bar{\sigma}_{2}\right)}{R^{\prime} R^{c}}\right)+\left(\frac{\bar{\sigma}_{2 z}}{Z^{s}}\right)^{2}+\left(\frac{\bar{\sigma}_{z z}^{\prime}}{Z^{\prime}}\right)^{2}+\left(\frac{\bar{\sigma}_{z z}^{c}}{Z^{c}}\right)^{2}=1
$$

where:

$$
\begin{aligned}
& \bar{\sigma}_{1}, \bar{\sigma}_{11}=\text { In-plane principle stresses in the } \\
& \text { resin layer } \\
& \bar{\sigma}_{s z}=\text { Vectorial sum of the intertaminar } \\
& \text { shear stresses, } \sigma_{z=} \text { and } \sigma_{y z} \\
& \bar{\sigma}_{z z}=\text { Average interlaminar normal stress } \\
& R^{\prime}=\text { Tensile strength of resin } \\
& R^{c}=\text { Compressive strength of resin } \\
& Z^{c}=\text { Interlaminar shear strength of ply } \\
& Z=\text { Interlaminar tensile strength } \\
& Z^{c}=\text { Interlaminar compressive strength }
\end{aligned}
$$


The stress terms are shown in Figure 5 and the following paragraphs describe each of the terms in the above criterion:

The first term contains the in-plane stresses. At the free edge, the in-plane stresses are not zero and contribute to the stress condition and should be included. Their inclusion was treated from a von Mises perspective. The average in-plane stress terms $\sigma_{x x}, \sigma_{x y}$ and $\sigma_{x y}$ are rotated into principle stresses $\sigma_{1}$ and $\sigma_{11}$. These stresses can be considered in a von Mises relation; however the characteristic strength $\sigma_{\circ}$ may not be a traditional strength parameter for anisotropic materials. In addition, the resin layer is an epoxy system in this investigation which may exhibit different strengths in tension and compression. An examination was performed by Williams $^{32}$ where the von Mises criteria was applied to polymers exhibiting this effect. This resulted in the separation of the characteristic strength into the product of tensile and compressive strengths. In a laminate, these are assumed to be the transverse tensile and compressive strengths, $Y^{\prime}$ and $Y^{c}$. The in-plane term takes the form shown above. The threedimensional von Mises failure theory for isotropic materials was applied to the stress state in the resin, however it did not give satisfactory results. This can be attributed to the layer effect because of the thin layer in the $z$ direction.

The second term is the interlaminar shear term. It is the vectorial sum of the average interlaminar shear stresses $\sigma_{x a}$ and $\sigma_{y z}$. In many cases one of the two terms will significantly dominate the result, however they are both included. Assuming transverse isotropy the same strength value for interlaminar shear can be compared to both terms. Alternately the stresses can be considered individually as in the QDC.

The third term is the interlaminar normal term. It accounts for both tensile and compressive interlaminar normal stress contributions to delamination. It has been suggested in the literature that compressive interlaminar normal stresses do not contribute to delamination. In some cases these stresses were thought to inhibit delamination, but there is no physical evidence to suggest this. The average stress is compared to the interlaminar normal strengths. It is important to note that the $\sigma_{z z}$ term often exhibits a crossover point from tension to compression within a couple of ply thicknesses. Care should be taken to consider this when computing an average stress as it is possible for the stress state to average out to zero when actual tensile and compressive stresses exist within the region. This effect was not witnessed in this study. While the interlaminar tensile strength can be obtained though flatwise tension testing, the compressive value is difficult to obtain. Current experimental methods may not accurately predict this value requiring it to be estimated. These values are assumed as the transverse tensile strength, $Y$, and the transverse compressive strength, $Y^{c}$.

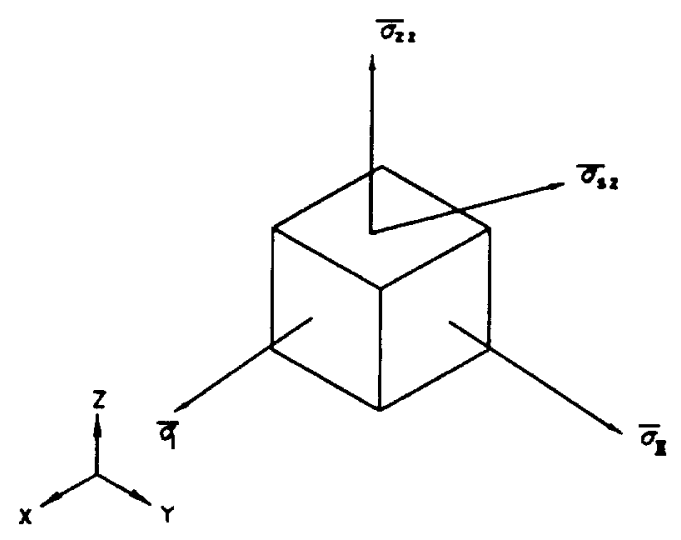

Figure 5: Stress directions for MVMDC

The QDC excludes terms because of their negligible impact on the resulting prediction, however there has been no physical evidence presented that some components should be excluded. It is often difficult to intuit how significant a stress value will be prior to the detailed stress analysis. In addition, modern analytical methods are frequently coded in computer programs which easily perform the additional computations. Therefore the entire six component stress state is represented in the MVMDC.

The validity of the MVMDC is shown by both applying it in a uniaxial configuration and by comparing it to in-plane criteria. An additional finite element analysis was run with all zero degree plies and the stresses were backed out for the thin resin layer in between two adjacent plies. When the MVMDC is applied to these results, a strength is predicted which is larger that the inplane strength of the laminate as predicted by in- 
plane criteria and experiment. The MVMDC does not indicate any failure prior to in-plane lamina failure.

Figure 6 shows the failure envelope for the MVMDC as compared to the Maximum Stress and Tsai-Wu criteria ${ }^{33}$. The MVMDC envelopes the in-plane criteria except for the small region in the first quadrant. For a condition where Classical Laminated Plate Theory holds, namely an infinite width laminate and strain continuity through the laminate, the MVMDC reduces to a plane stress von Mises relation based on resin values and does not indicate in-plane fiber behavior.

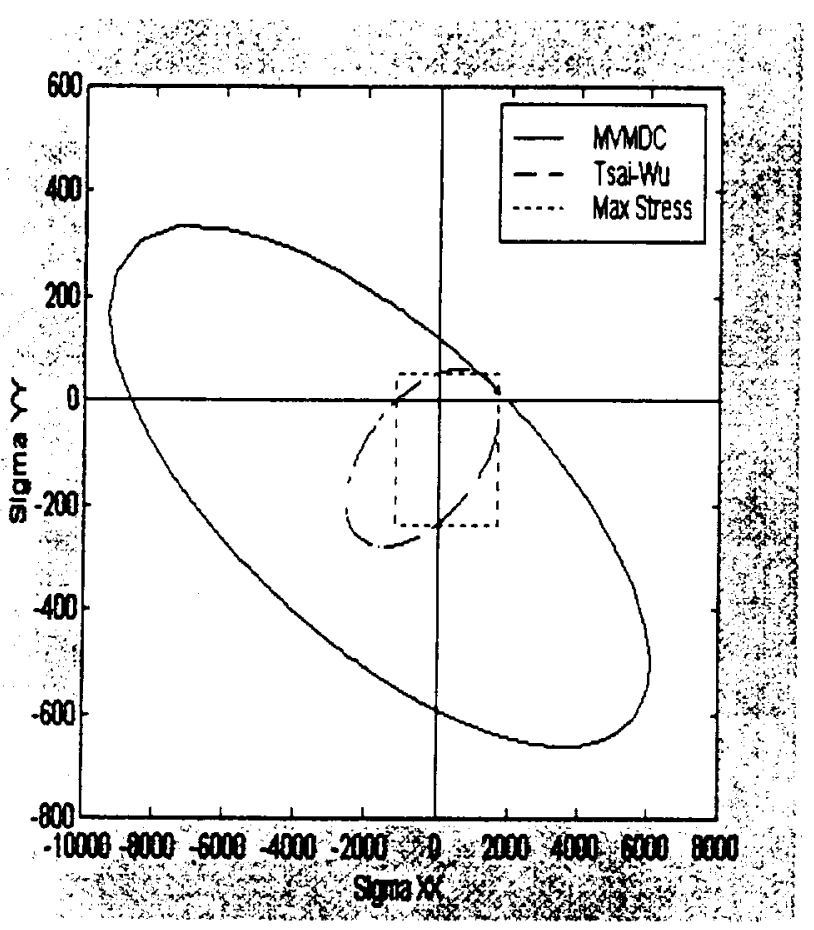

Figure 6: Modified von Mises Delamination Criterion Failure Diagram.

The three plots are very close in the first quadrant, however the region is very small and is a artifact of the material parameters used. This effect changes with different materials and the small overlap may or may not show up with different material systems. The first quadrant is shown in Figure 7. Regardless, the MVMDC was not intended for in-plane failure analysis. Lamina criteria such as Tsai-Wu or Maximum Stress should be used to predict in-plane behavior.

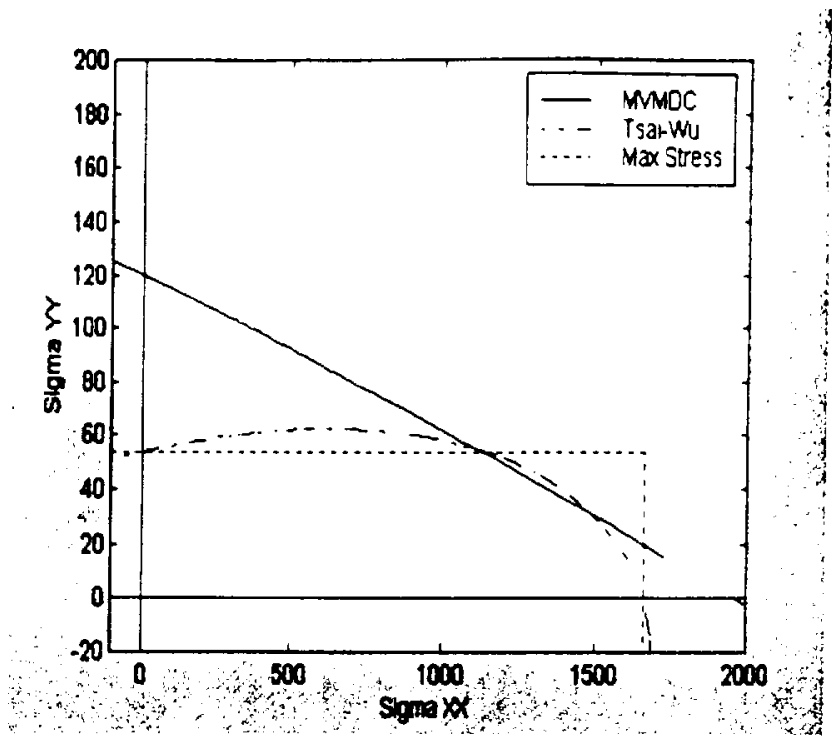

Figure 7: First quadrant of MVMDC failure diagram

\section{Correlation to Experimental Data}

The MVMDC was applied to the same data as the QDC and indicated delamination very well. Figures 8,9 , and 10 show the correlation of the MVMDC to the data presented with the QDC. The plots show the comparison of the predicted divided by the experimental value for each of the members of each laminate family. An accurate prediction has a value of unity while a number greater than one represents an overprediction. The laminate families are $[ \pm 15]_{n},[ \pm 15 / 0]_{n}$, and $[0 / \pm 15]_{n}$ where $n$ is one to five. The material system is AS1/3501-6 graphite epoxy with the following assumed strength parameters:

$$
\begin{aligned}
& R^{\prime}=Z^{\prime}=Y^{\prime}=54 \mathrm{MPa} \\
& R^{c}=Z^{c}=Y^{c}=236 \mathrm{MPa} \\
& Z^{\prime}=105 \mathrm{MPa}
\end{aligned}
$$

The values indicated by the MVMDC are in close agreement with the data. The averaging dimension was $0.402 \mathrm{~mm}$ or 1.75 ply thicknesses. This is seven elements of one quarter ply thickness width. This is about a $30 \%$ increase in the averaging dimension from the QDC investigation, however it is still on the order of what researchers suggest ${ }^{16.17}$. The averaging dimension was determined by selecting whole numbers of elements and comparing the resulting predictions to the data. This parameter is arbitrary; 
there is no evidence suggesting that this value represents any physical constant, however it has been suggested it may be a material parameter". The averaging dimension is used in this analysis solely as a fitting parameter and was optimized only to the mesh resolution of the model. The strength values were held constant reducing this to a one parameter model.

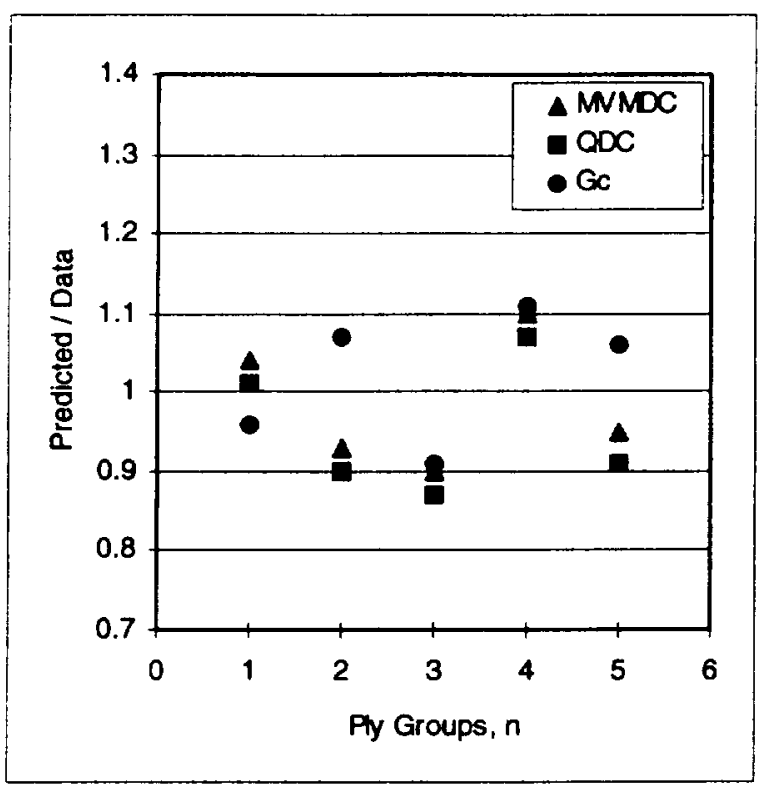

Figure 8: Data points for $[ \pm 15]_{n}$ laminate family

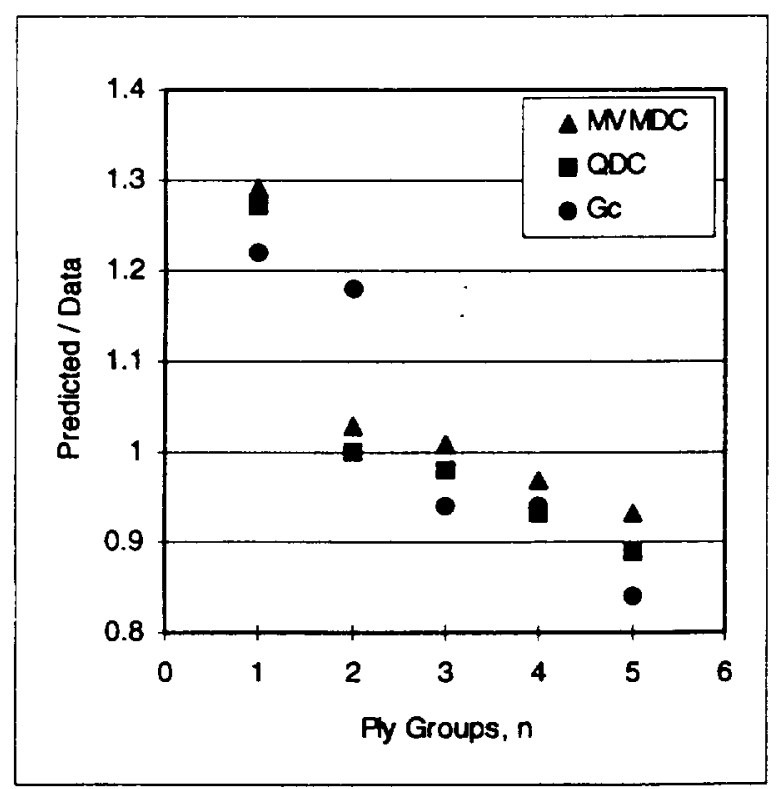

Figure 9: Data points for $[ \pm 15 / 0]_{n}$ laminate family

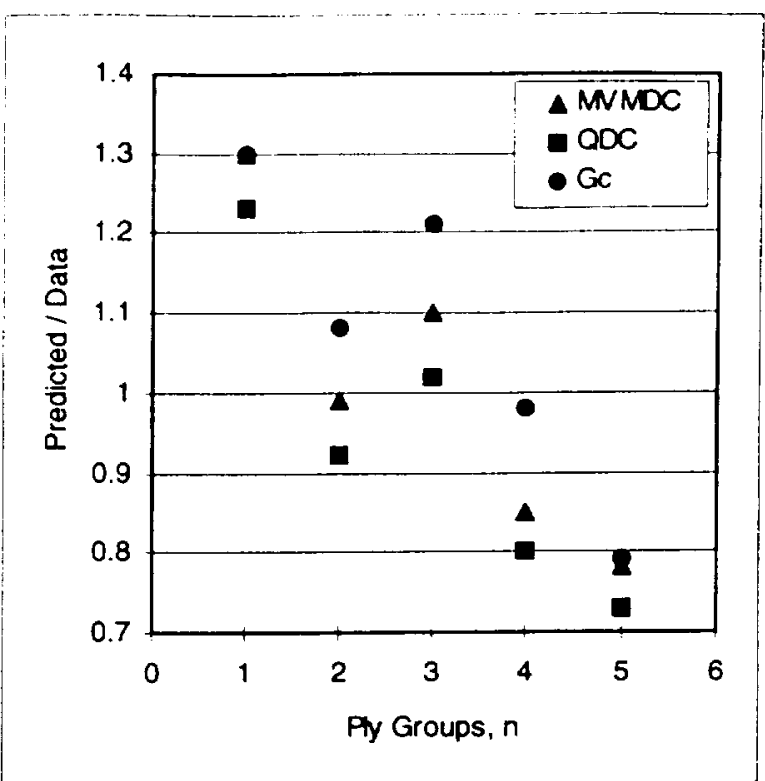

Figure 10: Data points for $[0 / \pm 15]_{n}$ laminate family

The MVMDC predicts delaminations for the $[ \pm 15]_{n}$ and $[0 / \pm 15]_{n}$ laminate families that is closer to the experimental values than those predicted by the QDC. The QDC predicts slightly closer values for the $[ \pm 15 / 0]_{n}$ laminate family than the MVMDC, but the difference is very small.

Correlation with other data in the literature shows excellent agreement with the MVMDC. An attempt was made to distinguish between delamination and transverse cracking. Some studies of delamination include specimens which show a propensity for transverse cracking ${ }^{24,34}$ (90 degree plies). Kim and Soni performed experiments and obtained some data which did not utilize laminates with angle plies greater than 30 degrees. The material system used is T300/934 with published values for ply properties and strengths ${ }^{30,35}$. The averaging dimension was changed to $1.25 \mathrm{t}$ for the best fit while the strength parameters were kept constant. The correlation to this limited data set is shown in Table 1:

\begin{tabular}{|c|c|}
\hline Laminate Layup & Predicted/Observed \\
\hline$[0,1 \pm 30]_{h}$ & 1.00 \\
\hline$[0,1 \pm 15]_{1}$ & 1.01 \\
\hline
\end{tabular}

Table 1: Correlation to data in the literature 


\section{Conclusions and Summary}

A brief history of the study of delamination and interlaminar stresses is presented as a background for the development of a delamination criterion. The following conclusions were drawn.

1. Delamination failure can be characterized as the failure of a resin rich layer or interphase inbetween ply sets. Finite element methods can be used to model this resin layer and compute the full stress state.

2. When considering the stress state in a resin rich layer in between ply sets, A full six component stress state is as valid as individual interlaminar stresses when considering the conditions for delamination.

3. The Modified von Mises Delamination Criterion has improved delamination prediction over the Quadratic Delamination Criterion and strain energy release rate methods. Strength values used were nominal material properties and could be obtained through normal experimental methods. The single parameter is the averaging dimension which is a curve fitting term which can be arbitrarily chosen and experimentally fit.

The proposed criterion can be easily applied when a full stress solution is generated. Finite element methods can easily provide the stress state for a variety of laminate configurations. This method can then be applied to evaluate candidate laminates for their propensity to delaminate and aid in the more efficient, durable and cost effective composite designs.

\section{References}

1. Puppo, A.H. and Evenson, H.A., Interlaminar Shear in Laminated Composites Under Generalized Plane Stress, Journal of Composite Materials, Vol 4, 1970, pp 204-220.

2. Pipes, R.B., and Pagano, N.J., Interlaminar Stresses in Composite Laminates Under Uniform Axial Extension, Journal of Composite Materials, Vol 4, 1970, pp 538-548.
3. Pagano, N.J., and Pipes, R.B., The Influence of Stacking Sequence on Laminate Strength, Journal of Composite Materials, Vol 5, 1971, pp 50-57.

4. Pagano, N.J., and Pipes, R.B., Some Observations on the Interlaminar Strength of Composite Laminates, International Journal of Mechanics and Science, Vol 15, 1973, pp 679688.

5. Pipes, R.B. and Pagano, N.J., Interlaminar Stresses in Composite Laminates - An Approximate Elasticity Solution. Presented as the Seventh US National Congress of Applied Mechanics, University of Colorado, 1974, ASME. pp 668-672.

6. Pagano, N.J., On the Calculation of Interlaminar Normal Stress in Composite Laminates, Journal of Composite Materials, Vol 8, 1974, pp 65-81.

7. Pagano, N.J., Free Edge Stress Fields in Composite Laminates, International Journal for Solids and Structures, Vol 14, 1978, pp 401-406.

8. Pagano, N.J., Interlaminar Response of Composite Materials, Composites Materials Series, 5, N.J. Pagano, Ed., Elsevier Publishing, 1989.

9. Pipes, R.B. and Daniel, I.M., Moiré Analysis of the Interlaminar Shear Edge Effect in Laminated Composites, Journal of Composite Materials, Vol 5, 1971, pp 255-259.

10. Jones, R.M., Mechanics of Composite Materials, Hemisphere Publishing, 1975.

11. Isakson G., and Levy, A., Finite-Element Analysis of Interlaminar Shear in Fibrous Composites, Journal of Composite Materials, Vol 5, 1971, pp 273-276.

12. Rybicki, E.F., Approximate Three-Dimensional Solutions for Symmetric Laminates Under In-Plane Loading, Journal of Composite Materials, Vol 5. 1971, pp 354-360.

13. Wang, A.S.D., and Crossman, F.W., Some New Results on Edge Effect in Symmetric Composite Laminates, Journal of Composite Materials, Vol 11, 1977, pp 92-106. 
14. Hsu, P.W. and Herakovich, C.T., Edge Effects in Angle-Ply Composite Laminates, Journal of Composite Materials, Vol 11, 1977, pp 422-428.

15. Wang, S.S. and Choi, I., Boundary-Layer Effects in Composite Laminates: Part 1 - Free Edge Stress Singularities, Journal of Applied Mechanics, Vol 49, 1982, pp 541-548.

16. Whitney, J.M. and Nuismer, R.J., Stress Fracture Criteria for Laminated Composites Containing Stress Concentrations, Journal of Composite Materials, Vol 8, 1974, pp 253-265.

17. Kim, R.Y., and Soni, S.R., Experimental and Analytical Studies on the Onset of Delamination in Laminated Composites, Journal of Composite Materials, Vol 18, 1984, pp 70-80.

18. Soni, S.R. and Kim, R.Y., Delamination of Composite Laminates Stimulated by Interlaminar Shear, Composite Materials: Testing and Design (Seventh Conference), ASTM STP 893, J.M. Whitney Ed., American Society for Testing and Materials, 1986, pp 286-307.

19. Pipes, R.B., and Kaminski, B.E., and Pagano, N.J., Influence of the Free Edge Upon the Strength of Angle-Ply Laminates, Analysis of the Test Methods for High Modulus Fibers and Composites, ASTM STP 521, American Society for Testing and Materials, 1973, pp 218-228.

20. Fish, J,C., and Lee, S.W., Three-Dimensional Analysis of Combined Free-Edge and TransverseCrack-Tip Delamination, Composite Materials: Testing and Design, ASTM STP 1059, S.P. Garbo, Ed., American Society for Testing and Materials, 1990, pp 271-286.

21. Reifsnider, K.L., Henneke, E.G. II, and Stinchcomb, W.W., Delamination in QuasiIsotropic Graphite-Epoxy Laminates, Composite Materials: Testing and Design (Fourth Conference), ASTM STP 617, American Society for Testing and Materials, 1977, pp 93-105.

22. Rybicki, E.F., Schmeuser, D.W., and Fox, J., An Energy Release Rate Approach for Stable Crack Growth in the Free-Edge Delamination Problem, Journal of Composite Materials, Vol 14 Supplement, 1980, pp 71-87.
23. Wang, A.S.D., and Crossman, F.W., Initiation and Growth of Transverse Cracks and Edge Delamination in Composite Laminates Part 1. An Energy Method, Carbon Reinforced Epoxy Systems. Part III, Volume Nine, Materials Technology Series, C.J. Hilado, Ed, Technomic Publishing, 1982, pp 165-181.

24. Crossman, F.W. and Wang, A.S.D., The Dependence of Transverse Cracking and Delamination on Ply Thickness in Graphite/Epoxy Laminates, Damage in Composite Materials, ASTM STP 775, K.L Reifsnider, Ed., American Society for Testing and Materials, 1982, pp 118139.

25. Wang, S.S., Fracture Mechanics for Delamination Problems in Composite Materials, Journal of Composite Materials, Vol 17, 1983, pp 210-223.

26. O'Brien, T.K., Characterization of Delamination Onset and Growth in a Composite Laminate, Damage In Composite Materials, ASTM STP 775, K.L. Reifsnider, Ed., American Society for Testing and Materials, 1982, pp 140-167.

27. O'Brien, T.K., Interlaminar Fracture of Composites, NASA Technical Report, NASA-TR85768, June, 1984.

28. Brewer, J.C., and Lagace, P.A., Quadratic Stress Criterion for Initiation of Delamination, Journal of Composite Materials, Vol 22, 1988, pp 1141-1155

29. Kassapoglou, C., and Lagace, P.A., An Efficient Method for the Calculation of Interlaminar Stresses in Composite Materials, Journal of Applied Mechanics, Vol 53, 1986, pp 744-750.

30. Lee, S.W., Rhiu, J.J., and Wong, S.C., Hybrid Finite Element Analysis of Free Edge Effect in Symmetric Composite Laminates, Technical Report, Department of Aerospace Engineering, University of Maryland, College Park, MD, June 1983.

31. Fish, J.C. and Lee, S.W., Strength of GlassEpoxy Laminates Based On Interply Resin Failure, Proceedings of the American Society of Composites Third Technical Conference, Seattle, WA, Sept. 1988, pp 242-252. 
32. Williams, J.G., Stress Analysis of Polymers,

$2^{\text {nd }}$ Ed, Halsted Press, New York, 1980, pp 76-91.

33. Tsai, S.W., Theory of Composites Design, Think Composites, 1992.

34. Rodini, B.T. Jr., and Eisenmann, J.R., An Analytical and Experimental Investigation of Edge Delamination in Composite Laminates, pp 441457.

35. Fiberite data sheet, CytecFiberite Corporation, 1995. 